\title{
Commentary: Cautious optimism for induction immunotherapy in resectable lung cancer
}

\author{
Michael Lanuti, MD
}

\author{
From the Division of Thoracic Surgery, Massachusetts General Hospital, Boston, Mass. \\ Disclosures: Author has nothing to disclose with regard to commercial support. \\ Received for publication April 8, 2019; accepted for publication April 9, 2019; available ahead of print May 15 , \\ 2019. \\ Address for reprints: Michael Lanuti, MD, Division of Thoracic Surgery, Massachusetts General Hospital, 55 \\ Fruit St, Founders 7, Boston, MA 02114 (E-mail: mlanuti@mgh.harvard.edu). \\ J Thorac Cardiovasc Surg 2019;158:277-94 \\ $0022-5223 / \$ 36.00$ \\ Copyright (c) 2019 by The American Association for Thoracic Surgery \\ https://doi.org/10.1016/j.jtcvs.2019.04.031
}

In this edition of the Journal, Bott and colleagues ${ }^{1}$ from Johns Hopkins and Memorial Sloan Kettering present the short-term outcomes and surgical and pathological results of a phase I clinical trial evaluating the feasibility and safety of 2 cycles of neoadjuvant nivolumab (human programmed death receptor-1 blocking antibody) in 21 patients diagnosed with stages I through IIIA non-small cell lung cancer (NSCLC). Clinical end points were feasibility and toxicity, and secondary end points were scientific correlates and treatment response. Invasive mediastinal staging was not mandatory but was performed as indicated. Of note, the majority of patients harbored clinical stage II (10/21) or stage IIIA (7/21) disease, with adenocarcinoma predominant $(67 \%)$. The key components of this important study include the following: (1) major pathologic response $(<10 \%$ viable tumor) observed in $45 \%$ of patients in the absence of a radiographic response, (2) no significant treatment toxicity that delayed curative surgery, and (3) $62 \%$ rate of conversion in patients with node-positive disease from a minimally invasive technique to open thoracotomy as a result of perihilar fibrosis. Despite a more difficult hilar dissection in patients with node-positive disease, remarkably, there were no blood transfusions and no operative deaths. This speaks to the surgical expertise at these institutions. Half of the patients had some postoperative morbidity, with the most common being atrial arrhythmia $(30 \%)$. The reported overall perioperative outcomes appear generally comparable with those reported in the modern era of open thoracic resections.

The study design can be criticized for the lack of mandatory invasive mediastinal staging to provide a more accurate disease stage of patients subjected to this experimental therapy. A second criticism would be that 7 patients with stage IIIA disease were recruited to this study for an unproven therapy that greatly deviated from the standard of care (no neoadjuvant chemotherapy or chemoradiotherapy before surgery). Major pathologic responses were only observed in $22 \%$ of patients with clinical stage IIIA NSCLC. In contrast, $56 \%$ of patients with stage II disease had a major

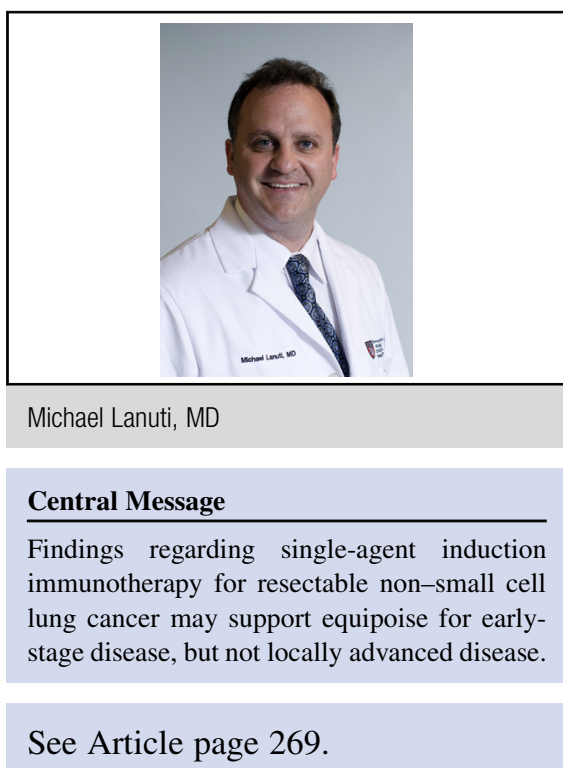

pathologic response. Because immune checkpoint inhibitors have demonstrated efficacy regardless of biomarker when combined with chemotherapy in advanced NSCLC (the KEYNOTE-189 trial $^{2}$ ), neoadjuvant chemotherapy in combination with immunotherapy may be a better strategy for locally advanced disease than single-agent checkpoint blockade.

The results of this study and its companion publication ${ }^{3}$ are intriguing and convey important contributions to the understanding of immune check point blockade in the neoadjuvant space of NSCLC. Bott and colleagues ${ }^{1}$ are to be commended on pushing the boundaries of single-agent induction therapy for a wide range of clinical stages, including locally advanced N2 disease. It is important to note that posttreatment diagnostic chest computed tomography did not predict pathologic response in this cohort. Investigation of fludeoxyglucose $\left({ }^{18} \mathrm{~F}\right)$ positron emission tomography or alternative novel molecular positron emission tomographic imaging probes, such as programmed deathligand $1^{4}$ or tumor-infiltrating $\mathrm{T}$ cells with anti-CD8 antibody ${ }^{5}$ should be considered when constructing these trials. As we move through a wave of clinical trials that explore immune checkpoint inhibition in resectable lung cancer, improving patient selection with biomarkers, tumor mutational burden, or genotyping should be paramount. Until we start curing patients with this new paradigm, deescalating therapy with single agent checkpoint blockade, 
particularly for locally advanced NSCLC, should be approached with caution.

\section{References}

1. Bott MJ, Yang SC, Park BJ, Adusumilli PS, Rusch VW, Isbell JM, et al. Initial results of pulmonary resection after neoadjuvant nivolumab in patients with resectable non-small cell lung cancer. J Thorac Cardiovasc Surg. 2019;158:269-76.

2. Gandhi L, Rodríguez-Abreu D, Gadgeel S, Esteban E, Felip E, De Angelis F, et al; KEYNOTE-189 Investigators. Pembrolizumab plus chemo- therapy in metastatic non-small-cell lung cancer. N Engl J Med. 2018;378: 2078-92.

3. Forde PM, Chaft JE, Smith KN, Anagnostou V, Cottrell TR, Hellmann MD, et al. Neoadjuvant PD-1 blockade in resectable lung cancer. N Engl J Med. 2018;378: 1976-86.

4. Niemeijer AN, Leung D, Huisman MC, Bahce I, Hoekstra OS, van Dongen GA, et al. Whole body PD-1 and PD-L1 positron emission tomography in patient with non-small cell lung cancer. Nat Commun. 2018;9:4664.

5. Postow MA, Harding JJ, Hellmann MD, Gordon MS, Tsai F, O'Donoghue JA, et al. Imaging of tumor infiltrating $\mathrm{T}$ cells with an anti-CD8 minibody (Mb) $89 \mathrm{Zr}$ IAB22M2C, in advanced solid tumors. J Clin Oncol. 2018;36(15 Suppl):e24160. 